\title{
Os sentidos atribuídos à cor e raça por alunos de uma escola pública
}

Marielle Costa Silva

Stela Maris Bretas Souza

\section{Resumo}

Esta pesquisa, do tipo descritiva e exploratória, buscou contribuir para crítica ao paradigma de desvalorização da infância e para promover discussão sobre as questões raciais, as quais muitas vezes são silenciadas. Este estudo objetivou investigar a autodeclaração de cor e raça de 37 crianças do $1^{\circ}$ ao $5^{\circ}$ ano do Ensino Fundamental de uma escola pública em Minas Gerais e oportunizar um tempo e espaço para refletir sobre a identidade racial e as vivências de discriminação na escola. Para isso, os instrumentos utilizados foram desenhos de autorretrato e grupos focais, analisados conforme a técnica de Análise de Conteúdo. Os resultados revelaram um amplo conhecimento e uso do vocabulário racial pelas crianças, sendo que a maioria considera os vocábulos cor e raça como sinônimos e evocaram o termo cor com maior familiaridade. Além disso, na maioria dos grupos pesquisados, observou-se a rejeição aos atributos físicos do grupo negro e a preferência em adotar termos referentes ao grupo branco. Foram relatadas vivências negativas por crianças negras em relação ao tema, o que pode influenciar na constituição de sua autoimagem. Ao escutar as vozes das crianças, foi possível valorizá-las e compreender que se apropriam e reconstroem os significados sócio-históricos e culturais formados sobre cor e raça ao longo do tempo. Sugere-se que sejam realizados mais estudos interligando as relações raciais e infância, sendo um campo relevante e pouco discutido pelas produções acadêmicas.

Palavras-chave: Crianças, Cor, Raça, Escola. 


\title{
The meanings attributed to color and race by students of a public school
}

\author{
Marielle Costa Silva Stela \\ Maris Bretas Souza
}

\section{Abstract}

This descriptive and exploratory research soughtto contribute to criticize the paradigm of childhood devaluation andto promote discussion on racial issues, which are often silenced.This study aimed to investigate the selfdeclaration of color and race among 37 children from first to fifty grade of elementary school from a public school in Minas Gerais and also to provide a time and space to reflect onracial identity and the experiences of discrimination at school. For this, the instruments used were self-portrait drawings and focus groups, analyzed according to Content Analysis technique. The results revealed a broad knowledge and use of racial vocabulary for children, and most of them consider the words color and race as synonyms and evoked the term color with greater familiarity. Furthermore, in most of the groups surveyed, it was observed rejection of the physical attributes of the black group and the preference for adopting terms referring to the white group. Some negative experiences have been reported by black children in relation to the theme, which can influence on the formation of their self-image. By listening to children' $s$ voices, it was possible to value them and to understand that they appropriate and reconstruct socio-cultural and historical meanings built on color and race over time. It is suggested that further studies be carried out linking race relations and children, being a relevant and little-discussed issue by academic productions.

Keywords: Children, Color, Race, School. 


\section{Introdução à cor e raça}

Este artigo é resultado de um estudo que objetivou investigar como as crianças de uma escola pública se autodeclaram em relação à cor e raça, assim como as situações de discriminação racial que vivenciam, a fim de refletir e discutir sobre o tema. Nesse sentido, oportunizou-se um tempo e espaço para os participantes expressarem sua identidade racial e suas vivências em relação à cor e raça, bem como foram verificadas as diferenças apontadas pelas crianças entre ambos os termos.

Este trabalho está pautado na interface entre os campos da Educação, Psicologia Escolar e Sociologia da Infância. Portanto, busca a valorização das crianças enquanto sujeitos sociais e históricos, por meio de uma postura ativa e dinâmica, em consonância com o amplo uso de vocabulário racial que realizam. Também propõe romper com a invisibilidade da infância no cenário científico, no sentido de problematizar o paradigma adultocêntrico nas representações sociais e nas pesquisas acadêmicas.

Sabe-se que o espaço da escola pública brasileira é marcado por diversas desigualdades, desafios e hierarquias, sendo focalizadas neste trabalho aquelas relativas à cor e raça. Para além disso, a escola também pode ser compreendida como lócus de transformação, movimento e produção de novas histórias e vivências mais positivas aos segmentos raciais e a convivência com a diversidade.

Para adentrar na temática das relações raciais, é fundamental retomar o contexto histórico brasileiro, constituído pela colonização e escravização. A partir disso, é relevante conceituar o termo raça. Em consonância com Gomes (2001, p. 85), adota-se o termo "raça" e seus correlatos em uma perspectiva de reapropriação, "entendida como um conceito relacional que se constitui histórica, política e culturalmente", diferentemente de seus antecedentes históricos que vinculavam o termo ao determinismo biológico. Portanto, raça no Brasil é entendida como um conceito socialmente construído, a partir da materialidade do corpo expressa pelas características fenotípicas da aparência física, em conjunto com elementos da origem ou ascendência racial.

Assim, considera-se que este é o vocábulo mais adotado pelos sujeitos sociais e, com isso, aproxima-se das dimensões do racismo na sociedade brasileira, que articula aspectos culturais e sinais físicos no corpo. Ao discutir sobre raça, deve-se atentar ao sentido de seu uso, aos significados atribuídos e ao contexto de quem fala (GOMES, 2005).

Rocha e Rosemberg (2007) destacaram que, no Brasil, o vocábulo cor é amplamente usado como imagem figurada para raça. Os autores também apontam que há uma gradação de cores, representada por termos intermediários como pardo; e por termos extremos, a exemplo de preto e branco. Ressalta-se o conceito de cor das pessoas em um sentido metafórico, de 
forma que os termos usados para cor da pele não são equivalentes aos mesmos termos referentes às cores de objetos do cotidiano.

Percebe-se que muitas crianças adotam vocábulos associados à cor da pele em um sentido literal, como por exemplo: bege, marrom e café com leite (ROCHA; ROSEMBERG, 2007). Além disso, é também observada uma maior familiaridade das crianças com a categoria cor, comparada à raça, sendo que esta última categoria geralmente provoca incômodo e dúvidas quanto ao seu conceito. Gomes (2005) apontou que a pergunta "Qual é a sua raça?” pode ser recebida de diferentes formas, com constrangimento, estranhamento ou até mesmo agressividade, dependendo do contexto e da pessoa em questão.

Sobre o conceito de raça, a pesquisa realizada por Rocha e Rosemberg (2007) revelou que as crianças e adolescentes participantes relacionaram o termo às raças animais e nãohumanas, na inexistência do conceito e na afirmação de uma raça humana única. Também observaram a tendência ao uso do termo negro para raça e dos termos preto e pardo para cor. Nesse sentido, é significativo traçar considerações a respeito dos processos de identificação de cor e raça no contexto brasileiro.

\section{Identificação de cor e raça no Brasil}

A partir das questões apresentadas, faz-se relevante apresentar as formas brasileiras de identificação de cor e raça. Osorio (2003) indicou que, no que se refere ao interlocutor, são considerados dois métodos de identificação: a autoatribuição ou autodeclaração de cor e raça, realizada pela própria pessoa; e a heteroatribuição ou heterodeclaração, na qual uma pessoa define a pertença racial do outro.

Osorio (2003) também apontou que há a autodeclaração espontânea, sem categorias predefinidas; e a autodeclaração induzida, na qual se escolhe uma categoria dentre as apresentadas, com base na classificação do Instituto Brasileiro de Geografia e Estatística (IBGE). Neste sentido, é relevante ressaltar que a própria autoatribuição de cor e raça segue uma lógica adulta, por meio da qual as crianças se definem. Dessa forma, segundo Nunes (2014) os estudos devem buscar além da simples autodeclaração, de forma a investigar os significados infantis atribuídos à cor e raça.

Em relação aos termos adotados, é possível perceber três modos de classificação racial, os quais são: o modo oficial, utilizado pelo IBGE, por meio das cinco categorias: branco, preto, pardo, amarelo e indígena. Há o modo popular múltiplo, marcado por grande diversidade de vocábulos acionados espontaneamente e há o modo binário, adotado pelo Movimento Negro, com o uso dos termos negro e branco (ROCHA; ROSEMBERG, 2007).

Nas autodeclarações espontâneas de cor e raça, o termo "preto/preta" vem sendo estigmatizado socialmente, sendo que, em contrapartida, há um aumento do uso do termo ISSN 2526-2882

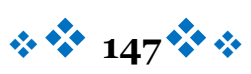


"negro". Porém, ainda se observa a predominância do termo "moreno", o qual é criticado por se tratar de um termo intermediário e ambíguo na gradação de cores, muitas vezes associado à estética branca, e assim é considerado uma das faces do racismo, como forma de se distanciar da cultura negra e evitar o uso dos termos "negro/a" e "preto/a" (OSORIO, 2003; TRINIDAD, 2011).

Este estudo considera que o termo negro engloba o conjunto de pessoas pretas e pardas, assim como é proposto pelo IBGE (OSORIO, 2003). A junção de ambos os segmentos se justifica pelo fato de que apresentam características socioeconômicas e físicas semelhantes; assim, pretos e pardos vivenciam discriminações potenciais e/ou efetivas de mesma natureza. O autor também destacou que quanto mais escura na escala de gradação de cores, aliado a outras marcas na aparência física, maior é a probabilidade de ser alvo de preconceito.

\section{Infâncias e discriminação racial nas escolas}

Ao longo da história, atribuiu-se à infância uma posição periférica, bem como a concepção de passividade diante dos adultos. Tal afirmação pode ser corroborada pelo número reduzido de pesquisas realizadas com crianças e, de maneira específica conforme percebido neste trabalho, pela escassez de estudos sobre o tema das relações raciais na infância (TRINIDAD, 2012).

Abramowicz e Oliveira (2012) apontaram as recentes concepções apresentadas pela Sociologia da Infância, que compreendem as crianças em um devir que não está relacionado às noções temporais cumulativas e lineares de um vir a ser um futuro adulto, mas busca visibilizar as infâncias reais e concretas no tempo presente. Isso significa que não há uma única infância, universal e atemporal, mas infâncias contextualizadas e históricas.

As crianças, desde a tenra idade, convivem com os recortes de gênero, sexualidade, cor e raça e diferenças de classe social. Ao tratar sobre a infância, Bento (2012) demonstrou que, desde bebês, as crianças se relacionam com seus pares e conhecem o mundo ao seu redor. As descobertas envolvem o toque de diferentes texturas de cabelo e a percepção de diferentes tons de pele, sendo que além de as crianças se apropriarem dos significados construídos em coletivos sociais, também criam sentidos e produzem culturas.

Gomes (2001) discutiu a rigidez da estrutura escolar atual no Brasil, na qual impera o paradigma branco, masculino, heterossexual e pode-se incluir que, na maioria das vezes, também marcada por relações de poder entre adultos e crianças/adolescentes. Assim, aquele que se distancia desse padrão estabelecido, em muitas situações, é discriminado e rotulado. Percebe-se que a violência racial brasileira do dia a dia, presente nas diversas instituições sociais, é enraizada e naturalizada, além de não depender apenas dos indivíduos que a praticam, ou seja, não se manifesta somente no nível individual, mas a nível institucional. 
As concepções de diversos atores sociais, como pessoas significativas na família, no bairro, nas escolas, nas organizações religiosas, dentre outros, reiteram as representações sociais entre "ser branco e ser bom e bonito" e "ser preto e ser ruim e feio", que são, em muitas situações, internalizadas pelas crianças. Dessa forma, crianças brancas podem se tornar mais assertivas enquanto brancas, valorizando sua identidade racial, enquanto crianças negras podem não reconhecer ou atribuir o seu pertencimento racial, devido a um sentimento de inferioridade criado por situações sociais de preconceito e de discriminação racial (BENTO, 2012).

Nesse sentido, estudos de Cavalleiro (2001) revelaram a presença de práticas em que professores adjetivam pejorativamente alunos negros, por meio do uso de expressões como: “cão em forma de gente" e "carvãozinho", de negligência quanto ao afeto para crianças negras em comparação às brancas, falta de acolhimento aos alunos que vivenciaram situações de discriminação, além da omissão da luta e das variadas histórias africanas e afro-brasileiras. É também possível notar que as ações racistas são legitimadas implicitamente quando são qualificadas como "brincadeiras" no espaço escolar, sem possibilitar um campo de diálogo e reflexão.

De acordo com Abramowicz e Oliveira (2012), na sociedade ocidental, impera o paradigma estético branco-europeu, sendo que as características físicas distantes desse perfil são consideradas atributos antiestéticos pelo imaginário social. Além disso, observa-se que a diversidade não é discutida e valorizada, sendo perpassada pelo silenciamento sobre essas questões.

O processo de socialização, iniciado na família e que se amplia nas escolas, poderia ser rico em experiências positivas para o desenvolvimento das crianças. Porém, em muitas situações, é sinônimo de vivências negativas para crianças negras, o que leva a fatores prejudiciais na constituição de sua autoimagem. Bento (2012) indicou que há fortes impactos negativos na subjetividade de crianças negras quando escutam continuamente mensagens implícitas e explícitas, que depreciam seus traços fenotípicos. Isso pode levar a criança a compreender o seu próprio corpo enquanto indesejável e relacionado à dor, bem como apresentar o desejo de mudá-lo e ter um corpo branco.

Nunes (2014) apontou que há crianças que sofrem precocemente com o racismo nos variados espaços sociais e que, assim, podem considerar difícil falar sobre o tema. Dessa maneira, atenta para a importância em se compreender essas dinâmicas sociais, pois apesar de conhecer o assunto, a criança pode silenciar e se omitir, sendo essencial escuta e acolhimento diante dessas situações.

Dessa maneira, evidencia-se que a relação entre crianças e adultos é marcada por uma hierarquia de poder, presente em uma sociedade adultocêntrica. Muitos adultos não ISSN 2526-2882

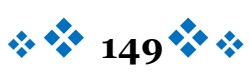


conversam com as crianças sobre o tema e não escutam seus discursos e as formas pelas quais se apropriam dos conceitos. Trinidad (2012) demonstrou que muitas famílias e agentes escolares desconhecem o sofrimento vivenciado pelas crianças negras em seu cotidiano. Também afirmou que para se discutir sobre a diversidade étnico-racial no ambiente escolar, é essencial um trabalho em parceria com a família.

Compartilhando das reflexões de Cavalleiro (2001), salienta-se que, apesar de muitas situações discriminatórias não se iniciarem na escola, encontram nesse espaço um terreno fértil para serem mantidas, constituindo-se em um campo frutífero para transformações positivas nesse cenário. Porém, atenta-se para não se culpabilizar a instituição escolar, uma vez que a mesma é atravessada por outros sistemas e instituições sociais.

\section{Identidade racial das crianças}

Gomes (2005) explanou que a identidade é um conceito complexo na literatura. A identidade racial indica um "nós" constituído pela coletividade e estabelece um sentido de pertencimento a um mesmo grupo. Assim, tal conceito é entendido como um processo em construção, de forma dinâmica, mutável e fluida no modo de ser e de se relacionar com os outros.

Bento (2012) discutiu que não há estudos aprofundados acerca do processo de formação da identidade na infância. A autora também apresentou que desde a idade compreendida entre 3 a 5 anos, a criança está ciente sobre as diferenças raciais e, assim, hierarquiza as relações.

Além disso, Trinidad (2011) também afirmou que desde os 3 anos de idade as crianças reconhecem a existência de pessoas negras e brancas e se identificam como membros de um grupo étnico-racial após a referida idade. Precocemente, as crianças já empregam as categorias raciais e conhecem os sentidos associados.

Ressalta-se que crianças mais novas manifestam o preconceito no plano verbal e tendem a transformá-lo em ações com o avanço da idade, ou seja, em idade pré-escolar utilizam o xingamento, podendo tornar-se violência física no Ensino Fundamental. Dessa forma, o desenvolvimento da identidade das crianças está ligado à forma com que a família, a escola e demais agentes sociais lidam com a dimensão racial (TRINIDAD, 2011, 2012).

Em seu estudo, Trinidad (2011) também indicou que a maioria das crianças brancas pesquisadas não apresentou o desejo de possuir características físicas distintas das próprias. Contudo, as crianças autodeclaradas brancas, que apresentavam características físicas semelhantes ao grupo negro, desejavam mudanças em sua aparência. Assim, as crianças consideravam motivo de sofrimento, vergonha e recusa apresentar traços próximos ao grupo negro, levando à rejeição de seu grupo racial.

ISSN 2526-2882 
Outro dado que caminha ao encontro dessa afirmação é o fato de que o número de crianças brancas que desejam ter outra cor de pele ou outro tipo de cabelo é consideravelmente menor que o número de crianças negras, as quais expressam desconforto por serem negras em muitas situações, além de naturalizarem a associação entre a cor da pele preta e a condição de inferioridade (BENTO, 2012).

Gomes (2005) criticou o mito da democracia racial, por meio do qual se postula que os diferentes grupos étnico-raciais convivem harmoniosamente e em situações de igualdade de oportunidades. Esse discurso encobre a discriminação racial contra negros e negras, bem como perpetua estereótipos, sendo que dados estatísticos e práticas cotidianas revelam as desigualdades raciais presentes nos variados espaços.

Observa-se que as famílias negras estão inseridas em um contexto de maior desigualdade social, o que implica nas condições de pobreza, que impactam em maior grau as crianças negras em comparação às crianças brancas e pobres. Em consonância com essa posição, dados relevantes do Fundo das Nações Unidas para a Infância (UNICEF, 2010) indicaram que a pobreza atingiu $32,9 \%$ entre as crianças brancas, sendo que esse número aumentou para $56 \%$ entre as crianças negras.

A partir dessas discussões apresentadas, Trinidad (2012) realçou o conhecimento infantil sobre os diversos grupos raciais. Assinalou que, ao escutar as vozes das crianças, podese verificar que desde a Educação Infantil ao Ensino Fundamental já se apropriam de significados construídos sociais, históricos e culturais, por meio de suas vivências e, assim, constroem suas identidades raciais. Bento (2012) também sugeriu que a identidade deve ser compreendida como um processo construído nas relações cotidianas. Assim, é essencial que haja transformações no sentido de ressignificar as concepções raciais, para buscar maior valorização da diversidade, seja nas escolas e em quaisquer outros espaços.

\section{Metodologia}

A pesquisa é do tipo descritiva e exploratória. De acordo com Gil (2002), as pesquisas exploratórias objetivam uma maior familiaridade com o tema, a fim de buscar maior compreensão a respeito de questões pouco investigadas. Já a pesquisa descritiva objetiva relatar características de uma população ou fenômeno.

Os participantes desta pesquisa foram 37 crianças do $1^{\mathrm{o}}$ ao $5^{\mathrm{o}}$ ano do Ensino Fundamental de uma escola pública em Minas Gerais. Esta escola possui 11 turmas nos anos iniciais do Ensino Fundamental. Os participantes foram identificados conforme sua respectiva escolaridade, por meio das siglas: A1 a A3 ( $1^{\circ}$ ano); B1 a B5 ( $2^{\circ}$ ano); C1 a C6 ( $3^{\circ}$ ano - Turma I); D1 a D9 ( $3^{\circ}$ ano - Turma II); E1 a E5 ( $4^{\circ}$ ano); F1 a F9 ( $5^{\circ}$ ano). 
Inicialmente, a pesquisa foi aprovada pelo Comitê de Ética a que esteve vinculada. Após esta etapa, realizou-se a visita à escola e o contato com a direção e corpo docente. Devido ao fato da produção dos dados ser desenvolvida no ambiente escolar durante o período de aulas, foi selecionada uma turma para cada ano escolar do $1^{\mathrm{o}}$ ao $5^{\mathrm{o}}$ para apresentação da proposta de pesquisa, por adesão da equipe docente. Duas professoras de $3^{o}$ ano demonstraram interesse na participação de suas turmas, fato que não ocorreu por parte dos demais professores que lecionavam em classes de mesmo ano escolar. Portanto, ambas as turmas do $3^{\circ}$ ano participaram desta pesquisa.

Para a produção dos dados, o número mínimo de participantes por grupo foi definido a três e o número máximo foi limitado a dez. Foi realizada a apresentação da proposta e o convite às crianças das turmas selecionadas. Posteriormente, as crianças interessadas, que iniciaram a participação neste estudo, assinaram o Termo de Assentimento e seus responsáveis assinaram o Termo de Consentimento Livre e Esclarecido (TCLE), documentos por meio dos quais são explicitados os cuidados éticos e a concordância sobre a participação na pesquisa. Além disso, este estudo se fundamentou nos pressupostos do Estatuto da Criança e do Adolescente (BRASIL, 1990), que considera crianças e adolescentes enquanto sujeitos de direitos e, portanto, devem ter seus direitos garantidos e suas falas escutadas e legitimadas.

Formaram-se seis grupos focais, divididos por escolaridade, sendo realizado um encontro com cada grupo, com duração média de uma hora e trinta minutos, totalizando seis encontros. Todos os encontros foram gravados em áudio e transcritos na íntegra, sob consentimento das crianças e dos familiares ou responsáveis. Os possíveis efeitos adversos em decorrência da gravação foram ao máximo minimizados. Os dados foram produzidos a partir de desenhos de autorretrato e grupos focais. O desenho enquanto instrumento para a pesquisa é uma técnica expressiva e lúdica para que a criança revele suas próprias percepções acerca de si e do mundo.

Para a confecção dos desenhos, foram utilizados um conjunto com doze gizes de cera, produzidos para representar diferentes cores de pele e um conjunto com doze cores diversas. Segundo Zimmermann et al. (2015), o uso do giz de cera apresenta um impacto formativo na aquisição de conceitos sobre as cores da pele, bem como tornou-se um símbolo cultural da infância e está relacionado à cor e à cognição.

O grupo focal é uma técnica que busca reunir informações diversas sobre um tema, a partir de um grupo de participantes selecionados. Assim, objetiva fomentar uma pluralidade de ideias na discussão e pauta-se na interação entre as pessoas para construir os dados relativos à pesquisa (TRAD, 2009).

No encontro com cada grupo, reiterou-se a proposta da pesquisa e foi estabelecido o contrato grupal dialogado com as crianças, por meio do qual, em linguagem acessível, foi ISSN 2526-2882

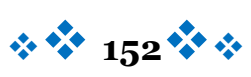


discutido sobre o sigilo da pesquisa, o anonimato dos participantes, a interrupção da participação a qualquer momento caso quisessem ou se sentissem desconfortáveis, além de que o encontro não buscava julgar ou avaliar respostas "certas" ou "erradas", mas sim escutar, compreender e refletir sobre o tema.

Além disso, estando ciente de que a discussão sobre este tema de pesquisa pode provocar diferentes sentimentos conforme cada pessoa ou contexto, a pesquisadora enfatizou que estaria à disposição para conversar e acolher as crianças em qualquer situação desconfortável que pudesse surgir, bem como intervir em grupo em casos de preconceito ou discriminação. Sabe-se também que os diálogos entre as crianças no momento da pesquisa, muitas vezes, refletem situações cotidianas semelhantes que ocorrem no dia a dia. Por meio do grupo focal, todos os diálogos foram mediados pela pesquisadora, a fim de acolher, discutir e problematizar o que era dito ou vivenciado.

Nos grupos, utilizou-se como método a autoatribuição ou autodeclaração espontânea de cor e raça. Solicitou-se às crianças que desenhassem a si próprias e escrevessem na folha o próprio nome, idade, qual a sua cor e qual a sua raça. Assim, mediou-se cada grupo focal por meio da escuta às falas das crianças, a fim de oportunizar um tempo-espaço para reflexão sobre a própria identidade étnico-racial e os sentidos atribuídos em relação ao tema. A análise dos dados se embasou em cálculos de estatística básica e na técnica de Análise de Conteúdo proposta por Bardin (1995), apresentando a pré-análise, exploração do material e interpretação dos resultados, divididos pelas categorias analisadas.

\section{Resultados e Discussão}

Os resultados encontrados revelam que as crianças apresentam um amplo conhecimento sobre o tema, uma vez que as relações raciais permeiam a vida cotidiana. Os dados foram divididos pela frequência total dos termos evocados por autodeclaração de cor e raça e pelos grupos conforme a escolaridade.

\section{Autodeclaração de cor}

A Tabela 1 apresenta os termos evocados para autodeclaração escrita de cor pelos participantes do $1^{\circ}$ ao $5^{\circ}$ ano. Verifica-se a alta frequência de uso dos termos morena e morena clara. Trinidad (2011) apontou que, devido à categoria morena ser considerada intermediária, o seu uso é frequente, bem como pode ser adotado para evitar os vocábulos preta e negra, devido aos significados culturais negativos construídos em torno dos dois últimos termos. Osorio (2003) também teceu críticas ao uso social tão frequente do termo "moreno", por considerá-lo uma forma de reforçar o ideal de embranquecimento. 
Conforme apontado por Rocha e Rosemberg (2007), também pode ser observada a presença de vocábulos associados à cor da pele em sentido literal, no emprego dos seguintes termos pelas crianças: café com leite, marrom, marrom parecido com cor de pele, leite e leite com café.

Constatou-se o uso dos termos "branco" e suas variações, "negra" e "pardo", sendo que esses termos evocados espontaneamente condizem com o vocabulário proposto pelo IBGE, o que demonstra que as crianças também utilizaram, em menor frequência, as categorias oficiais brasileiras de classificação. Houve o uso da palavra "bastarda", porém a criança não explicitou os motivos pelos quais a escolheu e é possível atentar ao uso do termo "cor de pele", em referência à cor branca. Além da autodeclaração que foi proposta, em todos os grupos houve situações em que as próprias crianças heterodeclararam a cor de colegas da escola, que estão descritas nos resultados referentes aos grupos focais. Por fim, houve uma baixa frequência de não identificação da cor.

Tabela 1: Autodeclaração escrita de cor dos participantes do $1^{\circ}$ ao $5^{\circ}$ ano

\begin{tabular}{lc}
\hline Autodeclaração de cor & Frequência Relativa (\%) \\
\hline Morena & 32,4 \\
\hline Morena clara & 13,5 \\
\hline Café com leite & 8,1 \\
\hline Marrom & 8,1 \\
\hline Branco & 5,4 \\
\hline Negra & 5,4 \\
\hline Marrom parecido com cor de pele & 2,7 \\
\hline Branco parecido com moreno & 2,7 \\
\hline Branco queimado & 2,7 \\
\hline Moreno escuro & 2,7 \\
\hline Leite & 2,7 \\
\hline Leite com café & 2,7 \\
\hline Bastarda & 2,7 \\
\hline Pardo & 2,7 \\
\hline Cor de pele & 2,7 \\
\hline Não identificou & 2,7 \\
\hline Total & 100 \\
\hline
\end{tabular}

Fonte: As autoras (2019)

\section{Autodeclaração de raça}

A Tabela 2 apresenta os termos evocados para autodeclaração escrita de raça pelos participantes do $1^{\circ}$ ao $5^{\circ}$ ano. É possível verificar a alta frequência de crianças que não autodeclararam a sua raça, sendo que Gomes (2005) apontou uma maior familiaridade das crianças com a categoria cor, comparada ao termo raça.

Muitas crianças participantes empregaram o termo mamífero, revelando que o conceituaram em referência aos animais, em consonância com o estudo de Rocha e Rosemberg 
(2007). Apesar da alta frequência de uso do termo negra, a maioria dos autorretratos representados nos desenhos e os relatos das crianças indicaram o desejo de apresentar características físicas, como o tipo de cabelo, cor dos olhos e cor da pele, próximas às características brancas e a rejeição aos atributos negros, conforme apontado por Bento (2012) e Trinidad (2011).

Observou-se também uma menor frequência de uso do termo morena para raça, o que demonstra que o referido vocábulo foi mais evocado diante da autodeclaração de cor pelas crianças. Além disso, também foi possível identificar que houve o uso de termos em sentido literal, como se pode notar em: nescau, cinza, cinza misturado com marrom e café com leite.

Pode se observar a apropriação do termo "pardo" por um maior número de crianças, entretanto algumas utilizaram o termo "humana" em perspectiva biológica e não no sentido de raças socialmente construídas. Raça também foi relacionada ao cabelo preto, que é um elemento que compõe a aparência física; associada a uma religião e a um adjetivo que denota beleza, o que indica que as crianças atribuíram diferentes significados ao conceito.

Tabela 2 Autodeclaração escrita de raça dos participantes do $1^{\circ}$ ao $5^{\circ}$ ano

\begin{tabular}{lc}
\hline Autodeclaração de raça & Frequência Relativa (\%) \\
\hline Não identificou & 24,3 \\
\hline Mamífero & 16,2 \\
\hline Negra & 13,5 \\
\hline Parda & 8,1 \\
\hline Nescau & 8,1 \\
\hline Morena & 8,1 \\
\hline Humana & 5,4 \\
\hline Cinza & 2,7 \\
\hline Cinza misturado com marrom & 2,7 \\
\hline Café com leite & 2,7 \\
\hline Cabelo preto & 2,7 \\
\hline Católica & 2,7 \\
\hline Linda & Fonte: As autoras (2019) \\
\hline Total & 2,7 \\
\hline
\end{tabular}

Após a análise da frequência total de autodeclaração de cor e raça, na seção seguinte foi discutido sobre os resultados divididos de acordo com a escolaridade, assim como as vivências escolares e os sentidos atribuídos à cor e raça pelos participantes, por meio dos grupos focais. 
$\mathbf{1}^{\circ}$ ano

Em relação ao termo cor, foi possível perceber que as crianças o mencionaram em relatos sobre suas vivências e na própria autodeclaração. Inicialmente, as três crianças se autodeclararam: preta (A1); morena escura (A2) e cor da pele escura (A3). Entretanto, tais termos foram substituídos pelos vocábulos morena e morena clara. Percebe-se que ao serem questionadas verbalmente sobre a própria cor, as três crianças se autodeclararam com termos próximos aos atributos físicos do grupo negro; entretanto, tais vocábulos foram substituídos por termos mais próximos do grupo racial branco. Foi possível notar que as crianças deste grupo utilizaram a categoria morena para evitar o uso das categorias preta e negra.

Em relação à raça, as crianças apresentaram dúvidas e evocaram dois conceitos, referindo-se à cor da pele e à raça dos animais. As participantes A1 e A2 não autodeclararam sua raça. O participante A3 utilizou o mesmo termo "morena" para autodeclarar sua cor e raça, o que indica que ele entende ambos os conceitos com sentidos equivalentes.

Enquanto desenhavam, houve um diálogo sobre os cabelos das meninas participantes:

A2: Eu desenhei eu [sic] de Maria Chiquinha, o meu cabelo cacheado. O [cabelo] da minha prima é tão liso, mas tão liso, que ele nunca embaraça. Eu gosto do meu cabelo pranchado, quando ele fica liso.

A1: Eu também gosto. Quando ele tá pranchado ele fica grandão. O meu cabelo é grande, só que com o cacho não deixa mostrar o grande, que ele tá [sic] grande.

A2: A minha tia é cabeleireira e quando minha mãe pede pra ela fazer alguma coisa [prancha no cabelo], aí na hora que minha tia acaba, na hora que eu olho no espelho dela, eu fico "Ahm!" [expressão de espanto], parece que nem é [sic] eu.

Pesquisadora: O que vocês gostam no cabelo pranchado?

A2: É porque o meu cabelo é seco e duro, aí eu gosto é do cabelo liso.

A1: Ah, eu também. Ah eu sou doida pra ter o cabelo liso. Eu nunca gostei de cabelo seco.

É relevante observar que ambas as meninas se desenharam com o cabelo liso no autorretrato. As falas das participantes indicam um desejo de apresentar características físicas, como o tipo de cabelo, próximas aos atributos brancos, além da rejeição ao cabelo cacheado ou crespo, fato que caminha ao encontro das afirmações de Trinidad (2011) e Bento (2012), pois demonstra que as crianças percebem as diferenças raciais, bem como as hierarquizam entre seus pares nos espaços de convívio social.

Ao discutir sobre as vivências relacionadas à cor e raça na escola, atenta-se para o seguinte relato: 
Pesquisadora: O que vocês acham sobre a cor e raça na escola?

A1: Acho muito ruim! Ruim, ruim... porque o [disse o nome de um colega de turma] fica me chamando de... fica me xingando de preta. Eu acho que eu sou negra. Eu fico triste.

Após este relato, a pesquisadora seguiu com a devida escuta e acolhimento à criança. Por meio da fala da participante A1, é possível analisar que o colega mencionado utilizou o termo preta em uma situação de ofensa, sendo que neste contexto, apropriou-se do uso do vocábulo em um sentido negativo. A criança participante evita o uso do termo preta e adota o vocábulo negra para atribuição de sua pertença étnico-racial. Assim, demonstrou que conhece os termos preto e negro, mas prefere não empregá-los em suas autodeclarações de cor e raça.

A fala transcrita reforça a autodeclaração inicial da participante A1, em que se considera preta. O seu relato está em consonância com Bento (2012), uma vez que a criança atribui a sua raça ao grupo negro, porém rejeita esse pertencimento, atribuindo concepções negativas em relação ao seu próprio corpo, sendo perceptível o sofrimento nas relações cotidianas escolares.

\section{$\mathbf{2}^{\mathbf{o}}$ ano}

Em relação à cor, embora os participantes deste grupo tenham reconhecido a diversidade de cores entre as pessoas, afirmaram que "todos são iguais por dentro". Depreende-se que tais visões são aprendidas na escola e demais espaços sociais, os quais veiculam mensagens simbólicas pautadas no mito da democracia racial. Como afirmou Gomes (2005), desde a infância é disseminada a concepção de igualdade entre as pessoas, o que oculta as desigualdades e dificulta a discussão sobre a existência da discriminação e racismo no cotidiano do nosso país.

Enquanto desenhava, um dos participantes se referiu ao giz de cera de cor rosa claro/bege como "cor de pele". Em consonância com o trabalho de Nunes (2014), buscou-se promover um momento de reflexão e problematização em grupo sobre a existência de uma cor denominada "cor de pele", uma vez que há diversas cores de pele. Essa situação revela que o padrão de referência é branco, sendo relevante considerar a nomeação das cores uma construção sociocultural, a fim de não naturalizá-las, a partir da perspectiva também adotada por Zimmermann et al (2015).

Sobre o conceito de raça, as crianças a relacionaram às semelhanças físicas delas próprias com familiares e amigos, especificando características como a cor da pele, formato do rosto e cabelo. Também consideram raça enquanto sinônimo de cor. A participante B2 mencionou termos referentes às cores das pessoas, sinalizando uso de vocabulário racial no cotidiano, como pode ser observado nas seguintes falas: "Eu sei. Raça é a cor de cada um, eu 
acho que tem tudo a ver com a cor" (B1); "É uma raça que a gente tem, tipo cores da gente, tipo negro, tipo branco, tipo amarelo, tipo bege" (B2).

\section{$3^{\mathbf{o}}$ ano - Turma I}

Em relação ao conceito do termo cor, as crianças apresentaram as seguintes definições: "É uma coisa que dá um toque no corpo" (C1); “uma coisa que colore o corpo" (C2); "cor mesmo é preto e branco" $\left(\mathrm{C}_{3}\right)$. As respostas das crianças indicam que consideram cor uma característica visível do corpo, de forma que se sabe que, de fato, a classificação de cor e raça no Brasil é mais fundamentada na aparência do que em aspectos da origem racial. É relevante observar também que a participante $\mathrm{C}_{3}$ se fundamentou em dois extremos do contínuo de cores: preto e branco, sendo possível analisar que essas cores foram mencionadas por serem categorias raciais mais demarcadas e, portanto, menos ambíguas na composição racial da população.

Em relação ao termo raça, as crianças mencionaram quatro categoriais: a cor de pele; animais; referiram-se ao grupo indígena e a um colega do grupo $\left(\mathrm{C}_{4}\right)$, heterodeclarado "o mais escuro". Diante dessa heteroatribuição de pertença racial pelos colegas, C4 não se posicionou e apenas continuou seu desenho, tendo escolhido um giz de cera de cor mais escura para seu autorretrato. Tais categorias podem ser exemplificadas conforme as falas que seguem: "Raça do elefante, do animal. Raça do [citou o nome do participante $\mathrm{C}_{4}$ ], raça das pessoas" (C2); "cor da pele" $\left(\mathrm{C}_{3}\right)$; "raça tem a ver com os índios. ( $\left.\mathrm{C}_{5}\right)$

As crianças demonstraram dúvidas e constrangimento quanto ao vocábulo raça, conforme indicado por Gomes (2005), sendo frequente acontecer certo incômodo ao discutir sobre o tema, devido ao silenciamento que atravessa as relações raciais brasileiras. Um outro elemento de análise se constituiu a partir de que, além dos grupos indígenas, não foi citado nenhum outro grupo étnico-racial pela criança $\mathrm{C}_{5}$ e nem por nenhum outro participante deste grupo. Percebe-se que o vocábulo raça, nas escolas e demais espaços sociais, geralmente é associado ou se remete ao racismo e ao histórico de discriminação contra negros e indígenas ao longo do tempo, de forma que tal fato pode justificar porque a criança mencionou apenas os indígenas.

Em relação ao cabelo, outro elemento que compõe a raça, foi constituído esse diálogo no grupo:

C3: Meu cabelo vai ser enorme. Vai ser estilo Black Power.

C5: Black o que?

C3: Black Power

C2: É aquele cabelo arrepiado.

C3: Não é arrepiado. É uns cabelo [sic] preto enroladinho assim que nem o seu, só que eles é [sic] muito. 
A referência ao cabelo Black Power indica o conhecimento infantil acerca de um aspecto da cultura negra. Os adjetivos "arrepiado" e "preto" foram usados para caracterizar esse estilo de cabelo. É possível observar que a palavra "preto" foi usada para referência ao cabelo, mas a mesma não foi acionada por nenhuma criança desse grupo para autodeclaração de cor e/ou raça.

Na discussão sobre as vivências sobre cor e raça na escola, ressaltou-se uma manifestação positiva em relação à valorização da identidade racial do grupo negro, sendo que houve consonância entre a autoimagem representada no desenho e a descrição realizada pela participante $\mathrm{C}_{3}$, Eu gosto de mim. Eu gosto quando meu cabelo tá arrumado. Gosto de fazer penteado. Gosto de maquiagem. Gosto do meu cabelo cacheado, do meu rosto, das unhas. Eu gosto da minha cor, combina comigo. Tipo, se não fosse dessa cor, não seria eu, não seria desse jeito. $\left(\mathrm{C}_{3}\right)$

\section{$3^{\mathbf{o}}$ ano - Turma II}

Em relação ao termo cor, as crianças demonstraram interesse e novamente percebeuse um discurso de igualdade entre todos os seres humanos, assim como aconteceu no encontro do grupo do $2^{\mathrm{o}}$ ano. Foi possível observar, no início do encontro, a heterodeclaração de um participante, considerado "negro" e "o mais escurinho" por alguns colegas do grupo: "[Citou o nome do participante D6] é negro. Ele é o mais escurinho que tem aqui (D1); "Ei, isso é racismo!"(D2).

Logo em seguida, a participante D1 tapou a própria boca e riu. O comentário dela foi repreendido e considerado "racista" pelo colega D2, devido ao uso das palavras "negro" e "escurinho". Analisa-se que o uso de tais termos é considerado um "tabu" na sociedade, assim como por algumas crianças deste grupo, sendo o seu uso censurado e evitado, conforme demonstrado por Osorio (2003). Além disso, apesar do discurso de igualdade, os participantes demonstraram que reconhecem e nomeiam as diferenças raciais entre os colegas.

Percebe-se que o participante D6 não se manifestou em relação à fala da colega, apenas continuou o seu desenho, com um giz de cera de cor escura. Ele também não autodeclarou sua cor e raça e, após o desenho, não participou da discussão sobre o tema. A pesquisadora o acolheu nestes momentos e perguntou se ele gostaria de conversar individualmente, mas ele disse que queria apenas continuar o desenho. Diante disso, é possível refletir o exposto por Nunes (2014), sendo que muitas crianças vivenciam o racismo e experiências negativas em relação à cor e raça em seu cotidiano, podendo se omitir quanto ao tema.

Na discussão sobre raça, as crianças apresentaram muitas dúvidas. Quando a palavra foi mencionada no grupo, houve muitos risos e observou-se constrangimento em tratar sobre 
esse vocábulo. Houve a presença de falas que indicam a dicotomia entre a raça das pessoas e a dos animais, como no exemplo da participante D4: "Todo mundo tem uma raça só: a raça humana, mas tem raças dos animais também”.

\section{$4^{\circ}$ ano}

Nas discussões sobre cor, notou-se um discurso politizado por parte das crianças, ressaltando-se a importância do respeito e do combate ao racismo: "Cor é a gente não ter racismo" (E2); "Cada um tem uma cor diferente" (E3); "Eu conheço dois irmãos gêmeos e eles têm tudo igual: a mesma cor, da mesma cor de olho, do mesmo cabelo" (E1).

Os demais colegas concordaram com a afirmação da participante E2, porém sem explicitar o conceito do termo. Percebe-se que as falas dos participantes E1 e E3 também demonstram que se baseiam em exemplos cotidianos em seu entendimento sobre cor e que observam critérios na aparência física das pessoas.

Uma questão significativa a ser analisada é que, muitas vezes, esse discurso antirracismo não é transformado em ações concretas no dia a dia de várias escolas. Assim, estudos como aqueles desenvolvidos por Cavalleiro (2001), Bento (2012) e Trinidad (2011, 2012), denunciam as situações de preconceito e discriminação racial, vivenciadas por crianças negras nas escolas, de forma explícita e implícita, bem como o silenciamento dos agentes escolares sobre tais questões.

Em relação à raça, verificou-se referência aos animais; à cor da pele; e associação à classe socioeconômica: "Raça de cachorro eu sei o que é" (E1); "Raça é a gente, é a cor da gente" (E2); "Eu acho que raça é de pobre" (E5). Sugere-se que, ao evocar o vocábulo "raça", o participante E5 se remeteu às condições de pobreza e de vulnerabilidade social.

Neste grupo, em consonância com Gomes (2005), também foram observadas dúvidas e um estranhamento acerca do termo raça. As afirmações das crianças também revelaram a importância da promoção de um tempo-espaço para reflexão sobre si e o processo de contínuo de construção da identidade: "Tia, eu nunca parei pra pensar na minha raça" (E2); "Eu até sei o que é [raça], mas eu nunca reparei” (E3). O tema das relações raciais e, em especial o sentido da palavra raça, é compreendido pelas crianças, porém carece de maior problematização na escola, nas famílias, nos bairros e demais espaços sociais.

Depreende-se que usualmente os participantes não têm um tempo-espaço para refletir sobre si mesmos na perspectiva da identidade étnico-racial. Abramowicz e Oliveira (2012) ressaltaram que isso pode acontecer devido à escassez de práticas e pesquisas realizadas com crianças e as poucas oportunidades de escutá-las em suas vivências e aprendizagens. 


\section{$5^{\mathbf{o}}$ ano}

Os participantes deste grupo expressaram relatos de vivências em relação ao tema. Destaca-se que um dos participantes relacionou o cabelo de sua irmã, considerado Black Power, à condição de inferioridade e a um atributo antiestético, como demonstrado por sua fala: "O cabelo da minha irmã é Black Power, grandão assim. Feio demais" (F6). Segundo Cavalleiro (2001), tais exemplos demonstram que as crianças têm acesso e se apropriam do debate sobre as relações raciais, compartilhado no cotidiano.

Além disso, atentou-se também para o relato de uma das crianças:

Minha mãe é branca, minha tia é branca, só a minha vó que não é. A minha vó é preta. A cor da minha vó é tipo da minha, só que mais um pouquinho escura. Mas eu não gosto, porque o olho do meu vô é azul e da minha mãe é verde e eu não puxei meu pai e nem a minha mãe e nem meu vô. (F4).

Por meio do relato da participante $\mathrm{F} 4$, é possível analisar que ela empregou o termo "preta" para heterodeclarar a cor de sua avó. Apesar de se identificar com características do grupo negro, a criança demonstrou o desejo de ter os olhos claros, ou seja, uma característica física que remete ao padrão de beleza branco-europeu, que é amplamente valorizado pela sociedade.

Em relação ao termo raça, percebeu-se que as crianças mencionaram os animais; a família e as características físicas, aproximando-se dos conceitos apresentados por Nunes (2014) e Trinidad (2012). Neste grupo, os participantes ampliaram os significados sobre raça para as origens familiares e às semelhanças na aparência com membros da família.

Na discussão sobre raça, um colega de sala de aula, que não estava presente no grupo, foi heterodeclarado por meio da exibição do giz de cera de cor preta, sendo que após essa ação, algumas crianças riram e foi iniciado um diálogo:

F6: Tipo assim, o [citaram o nome do referido colega] é uma raça, aí não sabe se é uma raça preta ou se é outra cor.

F7: Não, ele não é preto não, isso aí ele não é não. Ele é marrom, ele é marrom. F6: Marrom? Ele é mais 'negoçado' [sic] que isso aqui [mostrou o giz de cera de cor preta]

Pesquisadora: E o que vocês pensam sobre isso?

F6: Ele é legal, mas só que todo mundo abusa dele.

F7: Todo mundo fica zoando ele, falando que ele é preto, que ele é feio.

F1: Ele é pequenininho, pretinho.

F7: Aquela orelha assim ó, 'olhão'.

F1: Porque a raça dele é... O olho dele é grande, a cor morena mais escura.

F6: O cabelo dele é igual bombril.

A heterodeclaração de cor perpassa pela identificação do outro, conforme indicado por Bento (2012), a visão dos pares impacta na formação da autoimagem da criança. Percebe- 
se que o colega negro referido pelo grupo foi citado várias vezes na discussão, sendo mencionado de maneira negativa. Ao vivenciar situações de racismo na escola e em outros espaços, há a possibilidade de que a criança discriminada se aproprie da concepção socialmente enraizada que relaciona o seu corpo negro à inferioridade, fato que precisa ser transformado em direção à valorização negra e também indígena.

A situação observada neste grupo explicita o preconceito racial, mas depreende-se que ações discriminatórias envolvendo a mesma criança ocorrem cotidianamente no ambiente escolar. Assim, o exemplo citado pelos participantes merece especial atenção, uma vez que as situações de preconceito apresentadas podem ser transformadas em ações concretas de violência física direcionadas ao colega negro, conforme pesquisado por Trinidad (2011, 2012).

Outro ponto relevante é que, ao evocar o termo raça, muitas crianças se remeteram apenas ao colega negro mencionado na discussão, sem relacionar o conceito à diversidade racial presente na turma escolar. A fala do participante $\mathrm{F} 7$ demonstra que seleciona as palavras e atribui um sentido negativo ao termo preto e prefere utilizar o vocábulo marrom para heterodeclarar a raça. A participante F1 empregou o termo "cor morena mais escura” para se referir ao colega, sendo que os termos extremos da gradação de cores, como "preto” e "negro", foram utilizados com menor frequência ou evitados.

\section{Considerações Finais}

A presente pesquisa oportunizou um tempo-espaço para reflexão sobre os sentidos atribuídos às questões de cor e raça e como se interligam ao processo de construção da identidade racial das crianças do Ensino Fundamental I, na escola pública pesquisada. Dessa maneira, os objetivos propostos neste estudo foram alcançados, uma vez que foi possível compreender como se autodeclararam e discutir vivências sobre o tema.

Dessa maneira, os resultados encontrados revelaram que as crianças apresentam um amplo conhecimento sobre o tema abordado. Este estudo também buscou atuar no sentido de desconstruir a redoma formada socialmente sobre as crianças, que as mantêm distantes das discussões sobre cor e raça. Concluiu-se que a maioria dos participantes demonstram maior familiaridade com o termo cor e apresentam constrangimento diante do vocábulo raça, sendo que um número considerável de crianças não identificou a sua raça. Nas discussões sobre cor e raça, percebeu-se que a maioria considera ambos os vocábulos enquanto sinônimos, bem como emprega termos semelhantes ou idênticos em ambas as autoatribuições de pertença.

Além disso, os termos "morena" e "moreno" foram os mais utilizados na autodeclaração de cor das turmas pesquisadas, sendo que o uso desses vocábulos revelou 
proximidade aos atributos estéticos do grupo racial branco em muitas situações, bem como uma alternativa para evitar o emprego dos termos mais escuros da gradação de cores.

$\mathrm{O}$ termo negro foi utilizado com maior frequência que o termo preto, em ambas as autodeclarações, sendo que esse último foi evitado e criticado, pois muitas crianças interpretaram o seu uso em sentido negativo, conforme as concepções socioculturais construídas ao longo da história.

Além disso, as crianças demonstraram conhecimento acerca das relações raciais, porém a maioria afirmou a igualdade entre todas as pessoas enquanto seres humanos. Foram relatadas situações de preconceito e discriminação racial explícitas e veladas no ambiente escolar, além do silenciamento sobre as questões, sendo que algumas crianças evitaram discutir sobre o tema no grupo focal.

Em todos os grupos, foi observada heterodeclaração de cor e raça em relação a outras crianças. Também ocorreram várias situações de rejeição aos atributos corpóreos e à estética negra, como a cor da pele e o tipo de cabelo, acompanhados pelo desejo de apresentar características físicas próximas ao grupo branco. Em comparação, observou-se um número reduzido de situações de valorização da identidade étnico-racial do grupo negro.

Tendo em vista as conclusões apresentadas, o presente trabalho suscita reflexões significativas para novas pesquisas: o espaço escolar tem contribuído para a valorização da diversidade étnico-racial e cultural das crianças e atores escolares, no sentido de oportunizar vivências positivas em relação à cor e raça para todas e todos?

Conclui-se que, muitas vezes, há a constante reafirmação dos atributos brancos como o paradigma estético na sociedade brasileira e a reprodução dos estereótipos raciais. Refletese sobre o impacto das experiências negativas na vida de crianças negras, sendo que o processo de construção de sua identidade pode estar marcado pelas mensagens sociais de um corpo indesejável. Clama-se que este mesmo corpo seja reconhecido como luta histórica, pela beleza, pela cultura e estética negra.

Assim, reitera-se a importância em se desenvolver novas pesquisas que enfoquem as crianças como atores principais, para que se expressem, produzam culturas, sejam escutadas e legitimadas em seus discursos. Sugere-se que sejam realizados mais estudos interligando as relações raciais e infância, sendo um campo pouco discutido pelas produções acadêmicas da área. Busca-se incentivar estudos sobre o tema abordado nas ciências humanas e sociais, a fim de proporcionar maior visibilidade às crianças e na valorização de uma sociedade multicultural e polifônica. 


\section{Referências}

ABRAMOWICZ, A.; OLIVEIRA, F. de. As relações étnico-raciais e a sociologia da infância no Brasil: alguns aportes. In: BENTO, M. A. S. (Org.). Educação infantil, igualdade racial e diversidade: aspectos políticos, jurídicos, conceituais. São Paulo: Centro de Estudos das Relações de Trabalho e Desigualdades - CEERT, 2012. Disponível em: http://portal.mec.gov.br/index.php?option=com_docman\&view=download\&alias= 11283-educa-infantis-conceituais\&category_slug=agosto-2012-pdf\&Itemid=30192. Acesso em: 24 fev. 2019.

BARDIN, L. Análise de conteúdo. Lisboa: Edições 70, 1995.

BENTO, M. A. S. A identidade racial em crianças pequenas. In: (Org.). Educação infantil, igualdade racial e diversidade: aspectos políticos, jurídicos, conceituais. São Paulo: Centro de Estudos das Relações de Trabalho e Desigualdades CEERT, 2012. Disponível em: http://portal.mec.gov.br/index.php?option=com_docman\&view=download\&alias= 11283-educa-infantis-conceituais\&category_slug=agosto-2012-pdf\&Itemid=30192. Acesso em: 24 fev. 2019.

BRASIL. Estatuto da criança e do adolescente. Lei federal $n^{\circ} 8069$, de 13 de julho de 1990. Rio de Janeiro: Imprensa Oficial, 1990. Disponível em: http://www.planalto.gov.br/ccivil_03/Leis/L8069Compilado.htm. Acesso em: 24 fev. 2019.

CAVALLEIRO, E. Educação anti-racista: compromisso indispensável para um mundo melhor. In . (Org.). Racismo e anti-racismo na educação: repensando nossa escola. São Paulo: Selo Negro, 2001. p. 141-160.

FUNDO DAS NAÇÕES UNIDAS PARA A INFÂNCIA (UNICEF). Campanha por uma infância sem racismo. 2010. Disponível em: http://portal.mec.gov.br/index.php?option=com_docman\&view=download\&alias= 9282-campanha-unicef-contra-racismo-helena-pdf\&category_slug=outubro-2011pdf\&Itemid=30192. Acesso em: 24 fev. 2019.

GIL, A. C. Como elaborar projetos de pesquisa. 4. ed. São Paulo: Atlas, 2002.

GOMES, N. L. Educação cidadã, etnia e raça: o trato pedagógico da diversidade. In: CAVAllEIRO, E. (Org.). Racismo e anti-racismo na educação: repensando nossa escola. São Paulo: Selo Negro, 2001. p. 83-96.

GOMES, N. L. Alguns termos e conceitos presentes no debate sobre relações raciais no Brasil: uma breve discussão. In: BRASIL. Educação anti-racista: caminhos abertos pela lei 10.639/o3. Brasília. Secretaria de Educação Continuada, Alfabetização e Diversidade. MEC, 2005, p 39-62.

$$
\text { ISSN 2526-2882 }
$$


NUNES, M. D. F. "Professora, ainda posso mudar de cor?” :as crianças pequenas e suas impressões sobre as relações raciais na escola. II Simpósio Luso-Brasileiro em Estudos da Criança. Pesquisa com crianças: desafios éticos e metodológicos. Faculdade de Educação da Universidade de São Paulo - FE/USP: 2014. Disponível em:http://www.acaoeducativa.org.br/fdh/wp-content/uploads/2013/o3/MighianDanae-Nunes.pdf. Acesso em:24 fev. 2019.

OSORIO, R. G. O sistema classificatório de "cor ou raça" do IBGE. Brasília: Instituto de Pesquisa Econômica Aplicada, 2003. (Texto para Discussão, 996).

Disponível

em:

http://www.ipea.gov.br/portal/index.php?option=com_content\&view=article\&id=4 212.Acesso em: 24 fev. 2019.

ROCHA, E. J. da; ROSEMBERG, F. Autodeclaração de cor e/ou raça entre escolares paulistanos(as). Cadernos de Pesquisa. São Paulo, 2007. Disponível em:http://www.scielo.br/scielo.php?pid=So100-

15742007000300012\&script=sci_abstract\&tlng=pt. Acesso em: 24 fev. 2019.

TRAD, L. A. B. Grupos focais: conceitos, procedimentos e reflexões baseadas em experiências com o uso da técnica em pesquisas de saúde. Physis, Rio de Janeiro, v. 19, n. 3, p. 777-796, 2009.

TRINIDAD, C. T. Identificação étnico-racial na voz de crianças em espaços de educação infantil, 221 p. Tese (Doutorado em Psicologia da Educação). São Paulo: Pontifícia Universidade Católica de São Paulo, 2011. Disponível em: https://tede2.pucsp.br/handle/handle/15994. Acesso em: 24 fev. 2019.

TRINIDAD, C.T. Diversidade étnico-racial: por uma prática pedagógica na educação infantil. In: BENTO, M.A.S. (Org.). Educação infantil, igualdade racial e diversidade: aspectos políticos, jurídicos, conceituais. São Paulo: Centro de Estudos das Relações de Trabalho e Desigualdades - CEERT, 2012. Disponível em: http://portal.mec.gov.br/index.php?option=com_docman\&view=download\&alias= 11283-educa-infantis-conceituais\&category_slug=agosto-2012-pdf\&Itemid=30192. Acesso em: 24 fev. 2019.

ZIMMERMANN, M. et al. Please pass me the skin coloured crayon! Semantics, socialisation, and folk models of race in contemporary Europe. Language Sciences, 2015. Disponível em: http://ac.els-cdn.com/So388000114000746/1-s2.oSo388000114000746- main.pdf?_tid=75378240-1b89-11e5 a07500000aacb361\&acdnat=1435271469_ec3f3cf4d48806of678da597a2e75e8b. Acesso em: 24 fev. 2019. 


\section{Biografia Resumida}

Marielle Costa Silva: Graduada em Psicologia pelo Centro Universitário do Leste de Minas Gerais (UNILESTE). Mestranda em Psicologia pela Universidade Federal de São João del-Rei (UFSJ), na linha de pesquisa Instituições, Saúde e Sociedade, vinculada ao Laboratório de Pesquisa e Intervenção Psicossocial (LAPIP).

Link do Lattes: http://lattes.cnpq.br/1624216276167106

e-mail: silva.marielle94@gmail.com

Stela Maris Bretas Souza: Graduada e Mestre em Psicologia pela Pontifícia Universidade Católica de Minas Gerais (PUC-MG). Professora dos cursos de Psicologia e Pedagogia do Centro Universitário do Leste de Minas Gerais (UNILESTE). Vicepresidenta e conselheira do Conselho Regional de Psicologia de Minas Gerais (CRPo4). Coordenadora das Comissões de Psicologia Escolar e Educacional e de Formação Profissional do Conselho Regional de Psicologia de Minas Gerais (CRPo4). Coordenadora estadual da Associação Brasileira de Psicologia Escolar e Educacional (ABRAPEE).

Link do Lattes: http://lattes.cnpq.br/1498687998489833

e-mail: smbretas@uol.com.br 